\title{
Silica gel functionalized with imidazolium group via click chemistry - new stationary phase for ion chromatography
}

\author{
D.A. Chuprynina, I.A. Lupanova, V.V. Konshin (D), Dzh.N. Konshina * (iD
}

Kuban State University, Department of Chemistry and High Technologies, 350040 Stavropolskaya st., 149, Krasnodar, Russia

* Corresponding author: jfox@list.ru

This article belongs to the regular issue.

(C) 2021, The Authors. This article is published in open access form under the terms and conditions of the Creative Commons Attribution (CC BY) license (http://creativecommons.org/licenses/by/4.0/).

\section{Abstract}

This manuscript describes the preparation of a simple effective ionexchange material based on silica gel, on the surface of which methylimidazolium bromide is fixed using a click reaction. The resulting material was used as a stationary phase for the separation and determination of $\mathrm{Cl}^{-}, \mathrm{NO}_{2}{ }^{-}, \mathrm{NO}_{3}{ }^{-}, \mathrm{I}^{-}$, and $\mathrm{SO}_{4}{ }^{2-}$ using ion exchange chromatography. The separation efficiency and retention factors for the selected anions were studied in the $\mathrm{pH}$ range $3.5^{-6.5}$. The proposed material was used for the determination of $\mathrm{Cl}^{-}, \mathrm{SO}_{4}{ }^{2-}$ in water and can be suggested for successful use in real water samples.

\section{Keywords}

click reaction

ion exchange

modified silica

Received: 06.08.2021

Revised: 16.11.2021

Accepted: 09.12.2021

Available online: 11.12 .2021

\section{Introduction}

The development of new anion-exchange phases with improved efficiency and selectivity is one of the topical problems of modern ion chromatography [1]. The selectivity of an anion exchanger is largely governed by the nature and structure of functional layer and the method of its attachment to the matrix surface. The efficiency of an anion exchanger depends on the type of material, as well as on the morphology and the packing mode of particles. Organic polymers can be considered as the most convenient and common matrices for the design of anion exchangers. Nevertheless, such materials as zirconia, alumina, and, especially, silica gel are quite often used for the preparation of organomineral materials, stationary phases in chromatography and adsorbents for solid-phase extraction. The disadvantage of silica materials is their limited stability at lower and higher $\mathrm{pH}$ values, especially in alkaline solutions. Silica-based anion exchangers are often used in the $\mathrm{pH}$ range 2.0-9.5. However, compared to organic polymers, silicabased ion exchangers have the advantages of higher chromatographic efficiency and greater mechanical stability. In addition, such materials are preferable for operation in the nonsuppressive version of ion chromatography with conductometric detection, since in this case it is necessary to use dilute eluents, which is possible with materials of low exchange capacity.

Silica gel-based sorbents are synthesized using a conventional approach, which consists in the surface modifi- cation with different functional groups. Functionalization through covalent attachment of a modifier to the matrix surface has a number of advantages. First, the required amount of sorption and ion-exchange centers is governed by the structure and amount of a modifier. Second, variation in the structure of a modifier can influence the capacity, efficiency, and separation selectivity of an ion. Third, there are cross linking agents which enable extending the working $\mathrm{pH}$ range to 9.2 without affecting the efficiency over the entire life cycle of a column [2].

Such surface-grafted anion exchangers have the advantage of a small thickness of the ion-exchange layer that favors an increase in the rate of mass transfer upon ion exchange and thereby makes it possible to separate ions with high performance and high selectivity [3].

Various classes of organic compounds are used as the surface modifiers of stationary phase matrices [4]. In recent years, there is a growing interest in the use of ionic liquids that enable a wide variation in the nature of a cationic moiety, which influences the properties of obtained materials [5-7].

Among ionic liquids, imidazolium salts gained widespread acceptance as modifiers. Examples of their use as efficient extractants capable of forming ion-associative complexes with simple and complex anions have been described. Such complexes are readily produced and quite stable and variation of functional groups in the cationic moiety of ionic liquids offer manifold possibilities to apply salts in different version of sample preparation: 
sorption concentration, liquid-liquid microextraction, and modification of stationary phases in gas and liquid chromatography $[7,8]$.

Materials with attached imidazolium salts have been used successfully as stationary phases in liquid chromatography for separation of caffeine, theophylline, theobromine [9], xylose, glucose [10], ephedrine [11], and vitamins [12], as well as for separation of organic and inorganic anions [13-15]. Due to the variety of available starting reagents, not only materials for supernatant columns, but also solid columns with attached ionic liquids have been synthesized $[16,17]$.

The aim of the present work was to obtain ion-exchange materials based on silica gel having a particle size of 8-12 $\mu \mathrm{m}$ with imidazolium salt covalently immobilized by click reaction and to study whether they can be used as a stationary phase for ion-exchange chromatography.

\section{Experimental}

\subsection{Reagents and instrumentation}

The sorbent was prepared using silica gel "Sorbfil" with a particle size of 8-12 $\mu \mathrm{m}$.

IR spectra were recorded on a Shimadzu IR Prestige spectrometer in a range of $400-4200 \mathrm{~cm}^{-1} \cdot{ }^{13} \mathrm{C}$ NMR spectra were measured using a $400 \mathrm{MHz}$ Bruker WB Avance III spectrometer operating at 9.39 Tesla equipped with a Bruker $\mathrm{H}-\mathrm{F} / \mathrm{X} 4 \mathrm{~mm}$ pencil $\mathrm{CP} / \mathrm{MAS}$ probehead. ${ }^{13} \mathrm{C}$ chemical shifts were referenced to external solid TSP ((trimethylsilyl)propionic acid sodium salt) standard. Crosspolarization technique from ${ }^{1} \mathrm{H}$ with spinning sideband suppression (CP TOSS), contact pulse durations of 2-4 ms at a MAS rate of $10 \mathrm{kHz}$ was used.

The thermal stabilities of modified silica gel samples were studied on an STA 409 PC Luxx synchronous thermal analyzer (Netzsch, Gemrany) in a temperature range from 30 to $1000{ }^{\circ} \mathrm{C}$ at a heating rate of $10{ }^{\circ} \mathrm{C} / \mathrm{min}$ in the air atmosphere in $\mathrm{Al}_{2} \mathrm{O}_{3}$ ceramic crucibles.

The $\mathrm{pH}$ value of working buffers was verified on an Expert-001 ionomer using a calibrated ESC-10608 combined glass electrode.

Chromatographic properties of the column packed with modified silica gel were studied using a modular highperformance liquid chromatograph from Shimadzu (Kyoto, Japan) including a CTO-2OA column thermostat, an LC-2OAD sp mobile phase feed module, and CDD-10A vp. conductometric detector. The volume of injection loop was $20 \mu \mathrm{l}$. Data were collected and processed using the LCsolution program.

\subsection{Column packing}

316 Stainless steel HPLC columns $(150 \times 2 \mathrm{~mm})$ (Phenomenex) were used. The chromatographic column was packed by the suspension method under a pressure of $13 \mathrm{MPa}$. A test portion of the modified silica gel was added to a $\mathrm{C}_{2} \mathrm{H}_{5} \mathrm{OH}-\mathrm{CHCl}_{3}$ solution $(1: 1, \mathrm{v} / \mathrm{v})$. The column was packed and the sorbent was compacted on exposure to ultrasound. After packing, the column was conditioned by passing iso-propanol in a volume equal to the 20 -fold volume of the packed column, next - bidistilled water, and then - a working mobile phase until the background signal has become constant.

\subsection{Synthesis of imidazolium-modified silica gel}

Acetonitrile (70 mL), 3-azidopropyl silica gel (5 g), 1-methyl-3-prop-2-yn-1-yl-1H-imidazolium (1 g), CuI (0.095 g), and $\mathrm{N}, \mathrm{N}, \mathrm{N}^{`}, \mathrm{~N}^{`}$-(tetramethylethylenediamine) $(750 \mu \mathrm{L})$ were placed in a pressure flask with fluoroplastic screw cap and magnetic bar in the argon atmosphere. The resulting suspension was kept with vigorous stirring at $70{ }^{\circ} \mathrm{C}$ for $4 \mathrm{~h}$. Silica gel was separated on a Schott filter, washed with acetone, water, $2 \mathrm{M}$ hydrochloric acid, and again acetone and dried at $55^{\circ} \mathrm{C}$ for $12 \mathrm{~h}$ under a residual pressure of $5 \mathrm{~mm} \mathrm{Hg}$.

A portion of the resulting modified silica gel was further treated with a solution of hexamethyldisilazane in toluene for $8 \mathrm{~h}$ at $80{ }^{\circ} \mathrm{C}$.

\subsection{Determination of the total exchange capacity of the modified silica gel}

The maximum exchange capacity of the material was determined by titrimetry. The modified silica gel ( $0.5 \mathrm{~g}$ ) was agitated with $0.1 \mathrm{M}$ nitric acid (20 $\mathrm{mL}$ ) for $1 \mathrm{~h}$ [18]. Silica gel was filtered off and the amount of chloride ion released after the ion exchange reaction with $0.1 \mathrm{M} \mathrm{HNO}_{3}$ was determined by titrimetry in an aliquot portion of the filtrate. To the aliquot portion of filtrate $(5 \mathrm{~mL}), 0.05 \mathrm{M} \mathrm{AgNO}_{3}(5 \mathrm{~mL})$ was added and the excess of unreacted $\mathrm{AgNO}_{3}$ was titrated with 0.05 M KSCN using a saturated solution of $\mathrm{Fe}\left(\mathrm{NH}_{4}\right)\left(\mathrm{SO}_{4}\right)_{2}$ $(0.2 \mathrm{~mL})$ as an indicator. Titration was terminated after a sorrel color of the solution appeared due to the formation of iron rhodanate complex. The calculated total exchange capacity was $0.26 \pm 0.02 \mathrm{mM} / \mathrm{g}$. The capacity of the silanized material remained unchanged.

\section{Results and discussion}

The test object was an organomineral material based on silica gel with acovalently attached imidazolium group obtained by the azide-alkyne cycloaddition click reaction (Scheme 1).

In ${ }^{13} \mathrm{C}$ NMR spectrum for the modified silica gel with imidazolium salt two groups of spectral signals are seen. One group contains two signals at $\delta 124.4$ and 137.4 corresponding to the carbon nuclei in nitrogen-containing ring. Another group consists of spectral signals at $\delta 52,44.6$, $36.8,24.1$, and 17 , which corresponds to the carbon atoms of aliphatic $-\mathrm{CH}_{2}$ - fragments. The signal at $\delta 9.7$ corresponds to the $-\mathrm{CH}_{3}$ group.

Fig. 1 shows the IR spectra for the starting silica gel with covalently attached azide group and the imidazoliumbearing material obtained according to Scheme 1 . 
<smiles>C#CC[n+]1ccn(C)c1</smiles>

Scheme 1 Synthesis of the modified silica gel

Both spectra display a broad intense band at about $1300-1290 \mathrm{~cm}^{-1}$ corresponding to stretching vibrations of the siloxane ( $\mathrm{Si}-\mathrm{O}-\mathrm{Si}$ ) bond in silica. The intense absorption band at $1627 \mathrm{~cm}^{-1}$ is due to bending vibrations of water absorbed on the silica gel surface. The broad intense band at $3200-3500 \mathrm{~cm}^{-1}$ corresponds to the stretching vibrations of $\mathrm{O}-\mathrm{H}$ adsorbed on the water surface and silanol groups. The intense absorption band at $2106 \mathrm{~cm}^{-1}$ corresponds to stretching vibrations of the azido group grafted to the silica gel surface. In the spectrum of the silica gel sample obtained after the click reaction, the stretching vibration band of the azide group disappears, which suggests a successful click reaction on the silica gel surface.

The obtained batch of silica gel with a covalently immobilized group was divided into two portions. One portion was treated with a silanization reagent, hexamethyldisilazane (Scheme 2), in order to inactivate residual silanol groups, which are additional sorption centers.

The second portion of the material was used without additional treatment.

The heat stability is one of the key characteristics of sorption materials, since it governs the temperature range of their possible application (Table 1).

Similar temperature regions of weight loss and the presence of exothermic effect at about $350{ }^{\circ} \mathrm{C}$ can be distinguished for both samples of the modified silica gel.

Table 1 Thermal analysis data of silica gel samples

\begin{tabular}{lccc}
\hline Sil-im (h) & \multicolumn{3}{c}{ Sil-im } \\
\hline $\begin{array}{l}\text { Temperature } \\
\text { range, }{ }^{\circ} \mathrm{C}\end{array}$ & $\begin{array}{l}\text { Weight } \\
\text { loss, } \%\end{array}$ & $\begin{array}{c}\text { Temperature } \\
\text { range, }{ }^{\circ} \mathrm{C}\end{array}$ & $\begin{array}{c}\text { Weight } \\
\text { loss, } \%\end{array}$ \\
\hline $30-154$ & 4.7 & $30-165$ & 2.8 \\
$154-85$ & 6.1 & $165-325$ & 4.4 \\
$285-566$ & 10.7 & $325-460$ & 3.6 \\
$566-950$ & 0.2 & $460-900$ & 4.1 \\
\hline
\end{tabular}

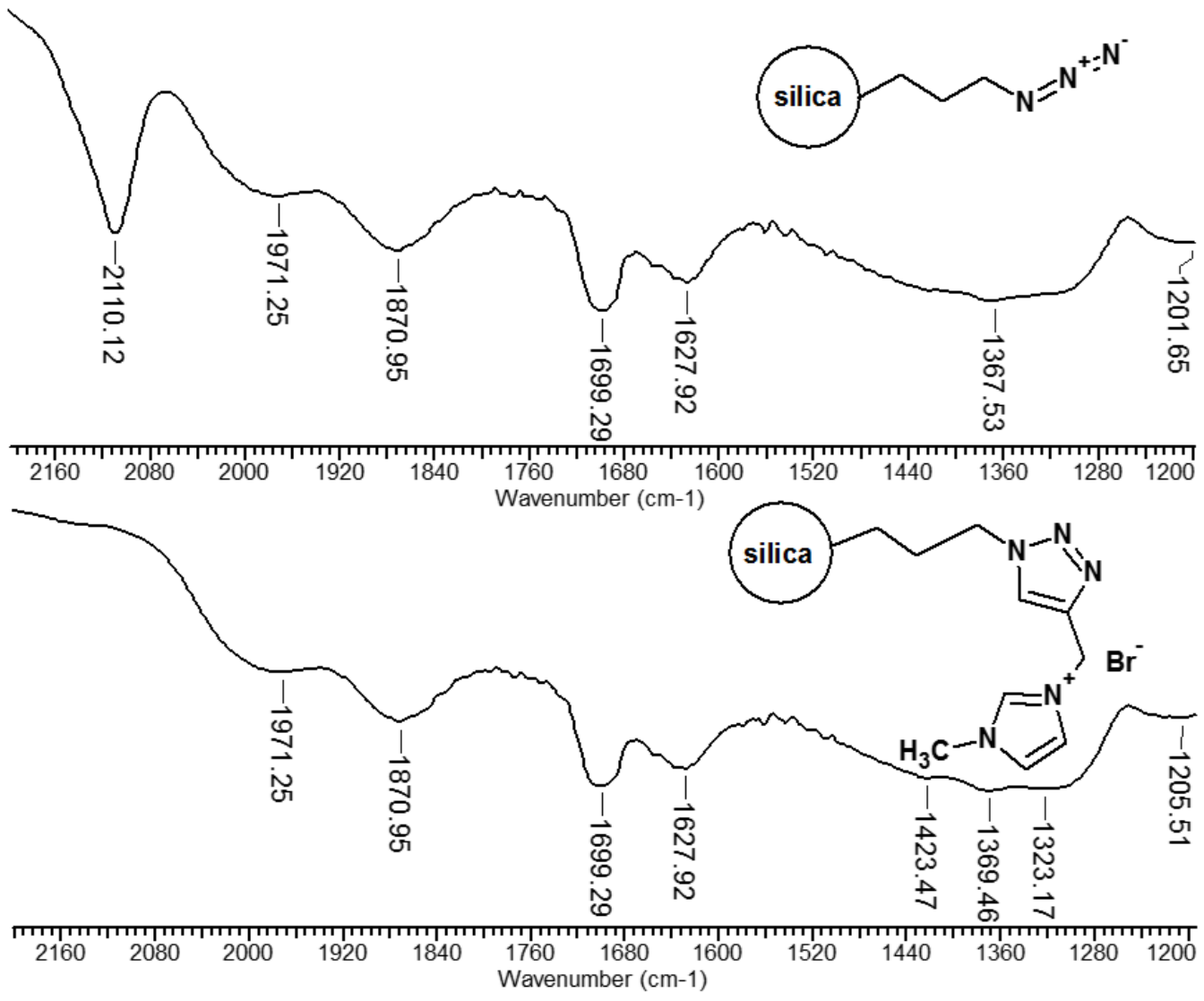

Fig. 1 IR spectra of the modified silica gel samples 
<smiles>Cn1cc[n+](Cc2cn(CCCC3CCC(O)CCC(O)CCC(O)C3)nn2)c1</smiles>

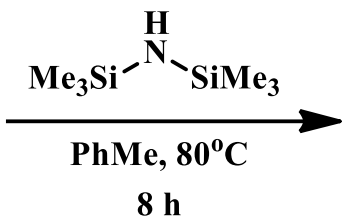

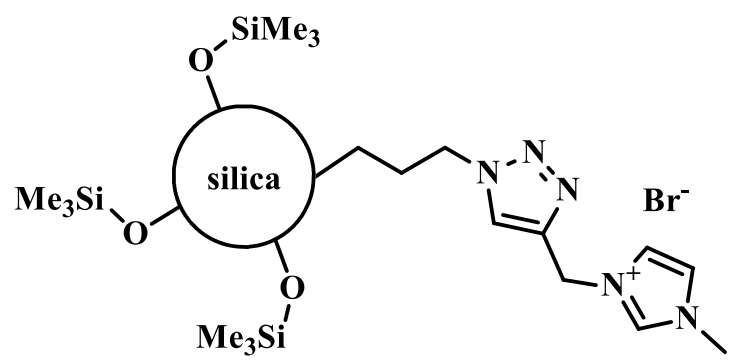

Sil-im (h)
Scheme 2 Synthesis of the modified silica gel

According to the literature data [19], the first section on the TG curve in a range from 80 to $170{ }^{\circ} \mathrm{C}$ is due to the evaporation of water adsorbed on the silica gel surface. Further decrease in the sample weight in a range from 170 to $900{ }^{\circ} \mathrm{C}$ corresponds to destruction of the functional organic layer. The total weight loss of modified silica gel samples at $950{ }^{\circ} \mathrm{C}$ was about $16.0-21.7 \%$.

Chromatographic conditions of the modified silica gels were studied in a single-column version of ion chromatography with non-suppressed conductivity detection. In such cases, for determination of anions on stationary phases possessing relatively low capacity values, diluted eluents based on aromatic acids, such as benzoic and phthalic acids, are preferred. The choice of the nature and composition of a buffer solution was caused by the fact that solutions based on phthalic acid possess high buffer capacity in the $\mathrm{pH}$ range recommended for stationary phases based on silica [20, 21].

A mixture of $\mathrm{Cl}^{-}, \mathrm{NO}_{2}{ }^{-}, \mathrm{NO}_{3}{ }^{-}, \mathrm{I}^{-}$, and $\mathrm{SO}_{4}{ }^{2-}$ anions was chosen as the model. The working parameters for chromatographic separation were chosen as follows: the eluent was $\mathrm{HOOCC}_{6} \mathrm{H}_{4} \mathrm{COOK}$ with $\mathrm{C}=2.5 \mathrm{mM}$ and $\mathrm{pH}=4$ [22].

The comparison of the efficiency of separation of the standard anion mixture by the studied materials under identical conditions demonstrates a considerable decrease in the plate numbers per meter $(\mathrm{N} / \mathrm{m})$ for Sil-im(h) (Table 2).

A

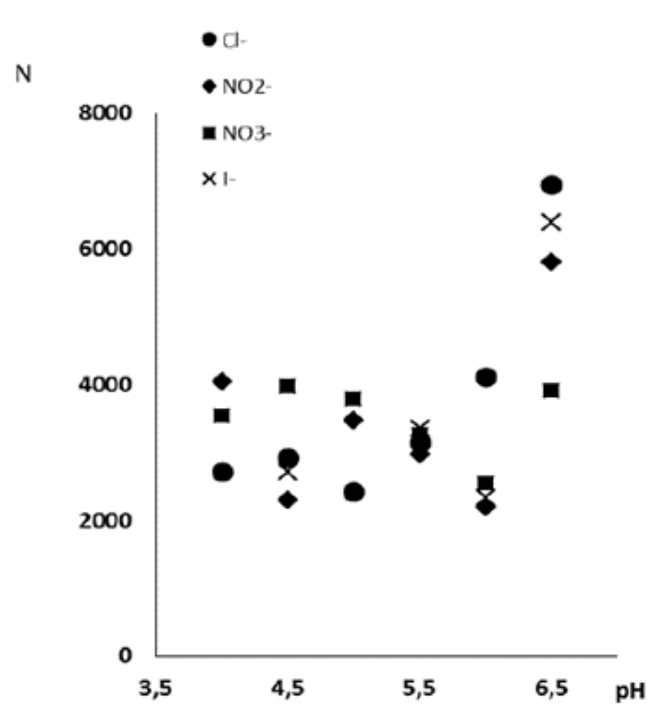

Table 2 Efficiency of anion separation $(\mathrm{N} / \mathrm{m})$ and retention time $\left(t_{\mathrm{r}}, \mathrm{min}\right)$ on the Sil-im and Sil-im (h) sorbents

\begin{tabular}{lcccc}
\hline \multirow{2}{*}{ Anion } & \multicolumn{2}{c}{ Sil-im } & \multicolumn{2}{c}{ Sil-im (h) } \\
\cline { 2 - 5 } & $N$ & $t_{\mathrm{r}}$ & $N$ & $t_{\mathrm{r}}$ \\
\hline $\mathrm{Cl}^{-}$ & 3126 & 5.0 & 2720 & 11.8 \\
$\mathrm{NO}_{2}{ }^{-}$ & 10093 & 5.9 & 4045 & 14.2 \\
$\mathrm{NO}_{3}{ }^{-}$ & 8686 & 6.5 & 3546 & 17.8 \\
$\mathrm{I}^{-}$ & 6273 & 8.7 & 2808 & 29.6 \\
\hline
\end{tabular}

The addition of $\mathrm{NaOH}$ to the stationary phase results in an increase in the efficiency and higher rapidity of separation of some anions due to an increase in the eluting power of the mobile phase. Upon pH change from 4 to 6 , the concentration of hydrogen phthalate, an average-strength eluting ion, increases and, upon $\mathrm{pH}$ above 6 , divalent phthalate with high eluting ability becomes the main anionic form of the eluent. In addition, at $\mathrm{pH}$ close to 7 , the residual silanol groups on the surface of the anion exchanger, which can enter into ion exchange interactions, undergo almost complete ionization resulting in an increase in the separation efficiency (Fig. 2). The most efficient separation was observed at $\mathrm{pH}=6.5$; one can note a multiple decrease in the retention, which leads to a possibility of determining anions in lower amounts. No change in the elution order was observed, which indirectly suggests a predominant ion-exchange mechanism of anion separation on the proposed stationary phase.

B

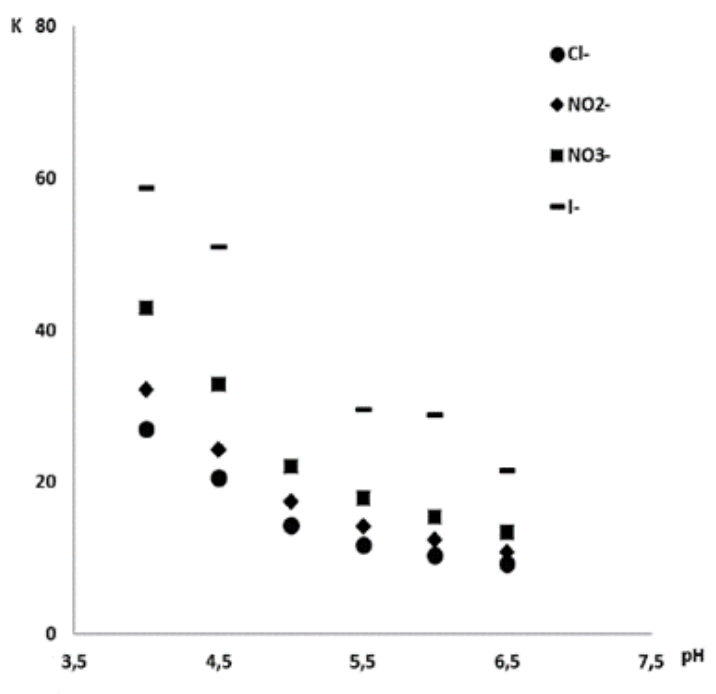

Fig. 2 The effect of $\mathrm{NaOH}$ content in the mobile phase on the separation efficiency $N(\mathrm{~N} / \mathrm{m})(\mathrm{A})$ and the retention $K$ of anions on the Sil-im(h) sorbent (B) 
The linearity of the method was tested using a series of inorganic anions standard solutions. Each point of the calibration plot was the average of three peak height measurements, because the baseline resolution of some anions couldn't be achieved without further dilution of the mobile phase and significant decrease of efficiency, which could cause a problem in the analysis of the samples with complex matrices. An example of a typical chromatogram is shown in the Fig. 3. The coefficient for calibration curves, the linear range and detection limits (defined as a signal three times the height of the noise level) as well as the quantification limits are presented in Table 3.

The comparison of the quantitative characteristics by the example of univalent inorganic anions demonstrates narrowing of the working concentration range on going from Sil-im to Sil-im(h) and, as a consequence, an increase in the limit of detection of an analyte.

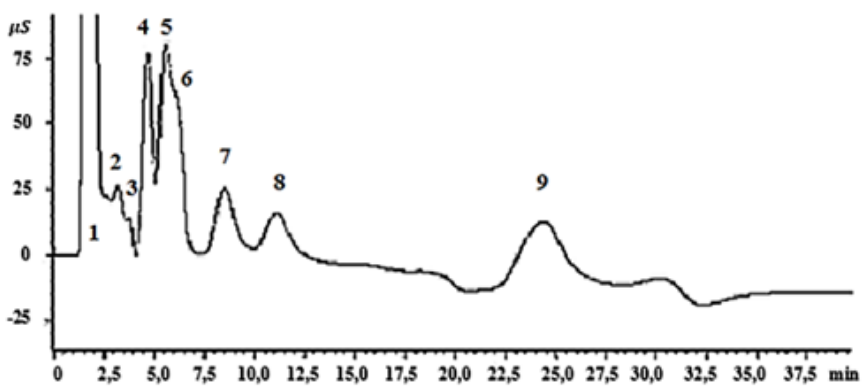

Fig. 3 Chromatogram obtained with the Sil-im stationary phase using anion-exchange conditions. Test mixture: 1) $\mathrm{F}^{-}$; 2) $\mathrm{CH}_{3} \mathrm{COO}^{-}$; 3) $\mathrm{IO}_{3}^{-}$; 4) $\mathrm{Cl}^{-}$; 5) $\mathrm{NO}_{2}^{-}+\mathrm{Br}^{-}$; 6) $\mathrm{NO}_{3}^{-}$; 7) $\mathrm{I}^{-}$; 8) $\mathrm{SCN}^{-}$; 9) $\mathrm{SO}_{4}{ }^{2-}$. Chromatographic conditions: mobile phase: $2.5 \mathrm{mmol} / \mathrm{L}$ HOOCC $_{6} \mathrm{H}_{4} \mathrm{COOK}$ with $\mathrm{pH}=4$, flow-rate: $0.3 \mathrm{ml} / \mathrm{min}$, injection volume: $20 \mu \mathrm{l}$ and detection: non-suppressed conductivity
However, the sensitivity of determination in this case increases, which is evidenced by an increase in the slope of the calibration curve. The error in the determination of standard solutions of the analyzed group of anions as estimated by the added-found method differs in a regular manner: no more than $6.2 \%$ for Sil-im and no more than $4 \%$ for Sil-im(h) (Table 4 ).

The applicability of the obtained ion-exchange material as a stationary phase in the ion-exchange chromatography was estimated by the example of Sil-im upon determination of inorganic anions in mineral water. Since the single-column non-suppressed ion chromatography used in this study does not possess a high sensitivity compared to two-column with suppressed conductivity detection, although it allows one to determine simultaneously in the isocratic mode weakly and strongly retained anions, it seems interesting to analyze real objects with a high content of anions. A "Lysogorskaya" bottled mineral drinking water relating to a group of chloride-sulfate ones was chosen as the test object (Table 5). The content of main macrocomponents was estimated by the calibration curve. To verify the determination accuracy of $\mathrm{Cl}^{-}$and $\mathrm{SO}_{4}{ }^{2-}$, their contents in the sample were estimated using a commercial column on a DIONEX ICS-30o chromatographic system with a possibility of eluent generation and suppressed conductivity detection.

The confidence intervals of ion determination obtained for different chromatographic determination systems overlap, which suggests the accuracy of the obtained data.

Table 3 Sensitivity factors and linear ranges of calibration curves for the studied anions

\begin{tabular}{|c|c|c|c|c|c|c|c|c|}
\hline \multirow[b]{2}{*}{ Anion } & \multicolumn{4}{|c|}{ Sil-im(h) } & \multicolumn{4}{|c|}{ Sil-im } \\
\hline & $\begin{array}{c}\text { Linear } \\
\text { range, } \\
\mathrm{mg} / \mathrm{L}\end{array}$ & $a^{*}$ & $R^{2}$ & $\begin{array}{c}\mathrm{LOD}^{* *} \\
\mathrm{mg} / \mathrm{L}\end{array}$ & $\begin{array}{c}\text { Linear } \\
\text { range, } \\
\mathrm{mg} / \mathrm{L}\end{array}$ & $a^{*}$ & $R^{2}$ & $\begin{array}{c}\mathrm{LOD}^{* *}, \\
\mathrm{mg} / \mathrm{L}\end{array}$ \\
\hline $\mathrm{Cl}^{-}$ & $40-160$ & 6227 & 0.9986 & 5.6 & $25-400$ & 3494 & 0.9985 & 1.9 \\
\hline $\mathrm{NO}_{2}^{-}$ & $20-160$ & 2210 & 0.9983 & 4.9 & $25-400$ & 2914 & 0.9990 & 1.6 \\
\hline $\mathrm{NO}_{3}^{-}$ & $40-160$ & 3859 & 0.9978 & 12.1 & $25-200$ & 484 & 0.9982 & 3.8 \\
\hline $\mathrm{I}^{-}$ & $40-160$ & 6325 & 0.9984 & 11.0 & $25-300$ & 685 & 0.9925 & 11.2 \\
\hline
\end{tabular}

*a - coefficient for calibration curves $(y=a x+b)$

${ }^{* *}$ LOD limits of detection $=S \cdot 3 \cdot 3, S-$ standard deviation of ten independent measurements of a blank sample

Table 4 Errors in the determination of the studied anions using the studied anion exchangers $(n=3, P=0.95)$

\begin{tabular}{|c|c|c|c|c|c|c|}
\hline \multirow{2}{*}{ Anion } & \multicolumn{3}{|c|}{ Sil-im(h) } & \multicolumn{3}{|c|}{ Sil-im } \\
\hline & Added, mg/L & Found, mg/L & $\Delta, \%$ & Added, mg/L & Found, mg/L & $\Delta, \%$ \\
\hline $\mathrm{Cl}^{-}$ & \multirow{4}{*}{80} & $77 \cdot 3 \pm 9 \cdot 9$ & -3.4 & \multirow{4}{*}{100} & $94.5 \pm 14.1$ & $-5 \cdot 5$ \\
\hline $\mathrm{NO}_{2}^{-}$ & & $78.3 \pm 10.2$ & -2.1 & & $94.0 \pm 14.1$ & -6.0 \\
\hline $\mathrm{NO}_{3}^{-}$ & & $80.8 \pm 10.4$ & 1.0 & & $97 \cdot 5 \pm 14 \cdot 3$ & 2.5 \\
\hline $\mathrm{I}^{-}$ & & $81.5 \pm 10.6$ & 1.9 & & $106.2 \pm 16.2$ & 6.2 \\
\hline
\end{tabular}

Table 5 Assessment of the anion content in the real sample using different chromatographic systems $(n=5, P=0.95)$

\begin{tabular}{|c|c|c|c|c|c|c|}
\hline Anion & & $\mathrm{Cl}^{-}$ & & & $\mathrm{SO}_{4}{ }^{2-}$ & \\
\hline Stationary phase & $C, \mathrm{mg} / \mathrm{L}$ & $C_{\text {claimed }}, \mathrm{mg} / \mathrm{L}$ & $S_{\mathrm{r},} \%$ & $C, \mathrm{mg} / \mathrm{L}$ & $C_{\text {claimed }}, \mathrm{mg} / \mathrm{L}$ & $S_{\mathrm{r},} \%$ \\
\hline Sil-Im & $2227 \pm 387$ & \multirow{2}{*}{$2200-7700$} & 1.93 & $7321 \pm 425$ & \multirow{2}{*}{$5500-9000$} & 0.17 \\
\hline Seporus A-UNI (HC-1) & $2845 \pm 345$ & & 4.13 & $7691 \pm 880$ & & 3.87 \\
\hline
\end{tabular}




\section{Conclusions}

In this work, the possibility of modifying the silica gel surface with an imidazolium salt using a click reaction was shown. The resulting ion exchange material was used as a stationary phase in the ion exchange chromatography method to separate $\mathrm{Cl}^{-}, \mathrm{NO}_{2}{ }^{-}, \mathrm{NO}_{3}{ }^{-}, \mathrm{I}^{-}$, and $\mathrm{SO}_{4}{ }^{2-}$. The study showed that the proposed material allows the determination of the selected anions with an error of 3.5-6.0\%. Moreover, the developed material showed good stability and repeatability of the results of the determination and separation of anions during the operation.

\section{Acknowledgements}

This publication was financially supported by the Ministry of Science and Higher Education of the Russian Federation (project no. FZEN-2020-0022).

\section{Conflicts of Interests}

The authors declare that they have no competing interests.

\section{References}

1. Zatirakha AV, Smolenkov AD, Shpigun OA. Preparation and chromatographic performance of polymer-based anion exchangers for ion chromatography. Anal Chim Acta. 2016;904:33-50. doi:10.1016/j.aca.2015.11.012

2. Alpert AA, Regnier FE. Preparation of a porous microparticulatee anion-exchange chromatography support for proteins. J Chromatogr. 1979;185:375-392. doi:10.1016/S0021-9673(00)85615-0

3. Collinson MM. Recent trends in analytical applications of organically modified silicate materials. Trends Anal Chem. 2002;21(1):31-39. doi:10.1016/S0165-9936(01)00125-X

4. Jal PK, Patel S, Mishra BK. Chemical modification of silica surface by immobilization of functional groups for extractive concentration of metal ions. Talanta. 2004;62:1005-1028. doi:10.1016/j.talanta.2003.10.028

5. Wang Y, Tian M, Bi W, Row KH. Application of ionic liquids in high performance reversed-phase chromatography. Int J Mol Sci. 2009;10:2591-2610. doi:10.3390/ijms10062591

6. Pino V, Afonso AM. Surface-bonded ionic liquid stationary phases in high-performance liquid chromatography - a review. Anal Chim Acta. 2012;714:20-37. doi:10.1016/j.aca.2011.11.045

7. Vidal L, Riekkola ML, Canals A. Ionic liquid-modified materials for solid-phase extraction and separation: a review. Anal Chim Acta. 2012;715:19-41. doi:10.1016/j.aca.2011.11.050

8. Shamsi SA, Danielson ND. Utility of ionic liquids in analytical separations. J Sep Science. 2007;30:1729-1750. doi: $10.1002 /$ jssc. 200700136
9. Bi W, Row KH. Comparison of different silica-based imidazolium stationary phases for LC in separation of alkaloids. Chromatographia. 2010;71:25-30. doi:10.1365/s10337-009-1380-9

10. Bi W, Zhou J, Row KH. Separation of xylose and glucose on different silica-confined ionic liquid stationary phases. Anal Chim Acta. 2010;677(2):162-168. doi:10.1016/j.aca.2010.08.004

11. Liu SJ, Zhou F, Xiao XH, Zhao L, Liu X, Jiang SX. Surface confined ionic liquid - A new stationary phase for the separation of ephedrines in high-performance liquid chromatography. Chin Chem Lett. 2004;15(9):106o-1062.

12. Qiu H, Jiang Q, Wei Z, Wang X, Liu X, Jiang S. Preparation and evaluation of a silica-based 1-alkyl-3-(propyl-3-sulfonate) imidazolium zwitterionic stationary phase for highperformance liquid chromatography. J Chromatogr A. 2007;1163(1-2):63-69. doi:10.1016/j.chroma.2007.06.001

13. Qiu H, Jiang S, Liu X. N-Methylimidazolium anion-exchange stationary phase for high-performance liquid chromatography. J Chromatogr A. 2006;1103(2):265-270. doi:10.1016/j.chroma.2005.11.035

14. Qiu H, Jiang S, Liu X, Zhao L. Novel imidazolium stationary phase for high-performance liquid chromatography. J Chromatogr A. 2006;1116(1-2):46-50. doi:10.1016/j.chroma.2006.03.016

15. Qiu H, Wang L, Liu X, Jiang S. Preparation and characterization of silica confined ionic liquids as chromatographic stationary phases through surface radical chain-transfer reaction. Analyst. 2009;134:46o-465. doi:10.1039/B809125K

16. Liu K, Tolley HD, Lawson JS, Lee ML. Highly crosslinked polymeric monoliths with various $\mathrm{C} 6$ functional groups for reversed-phase capillary liquid chromatography of small molecules. J Chromatogr A. 2013;1321:80-87. doi:10.1016/j.chroma.2013.10.071

17. Lin $\mathrm{H}$, Ou J, Zhang Z, Dong J, Zou H. Ring-opening polymerization reaction of polyhedral oligomeric silsesquioxanes (POSSs) for preparation of well-controlled 3D skeletal hybrid monoliths. Chem Commun. 2013;49(3):231-233. doi:10.1039/c2cc36881a

18. Iamamoto MS, Gushikem Y. Adsorption of metal ions from aqueous and ethanol solutions by silica gel functionalized with pyridinium ions. J Colloid Interface Sci. 1989;129(1):162-165. doi:10.1016/0021-9797(89)90426-8

19. Protsak IS, Kuzema PO, Tertykh VA, Bolbukh YM, Kozakevich RB. Thermogravimetric analysis of silicas chemically modified with products of deoligomerization of polydimethylsiloxane. J Therm Anal Calorim. 2015;121:547-557. doi: $10.1007 / \mathrm{s} 10973-015-4623-\mathrm{z}$

20. Sun M, Feng J, Wang X, Duan H, Li L, Luo C. Dicationic imidazolium ionic liquid modified silica as a novel reversed-phase/anion-exchange mixed-mode stationary phase for high-performance liquid chromatography. J Sep Sci. 2014;37(16):2153-2159. doi:10.1002/jssc.201400176

21. Haddad PR, Jackson PE. Ion Chromatography: Principles and Applications, Elsevier: Amsterdam; 1990. 775 p.

22. Konshin VV, Chuprynina DA, Lupanova IA, Konshina DzhN. Silica gel with covalently immobilized imidazolium salt as a new stationary phase for ion chromatography. AIP Conf Proc. 2020;2280(1):050028. doi:10.1063/5.0018424 